\title{
Sekolah Siaga Bencana SMPN 1 Kecamatan XI Tarusan, Kabupaten Pesisir Selatan, Provinsi Sumatera Barat, Indonesia
}

Hendra Saputra $^{1}$, Roswati ${ }^{2}$, Fatmawati ${ }^{3}$, Yulia Novita ${ }^{4}$ dan Nelvawita ${ }^{5}$

1,2,3,4,5 Program Pendidikan Geografi, Universitas Islam Negeri Sultan Syarif Kasim Riau

hendra.saputra@uin-suska.ac.id

\begin{abstract}
ABSTRAK. Program Pengurangan Risiko Bencana (PRB) berbasis sekolah bertujuan menciptakan komunitas sekolah yang siaga terhadap bencana. Tujuan Penelitian adalah untuk mengindentifikasi peran guru dalam menyelenggarakan SSB dan Kebijakan Sekolah Siaga Bencana. Jenis penelitian ini adalah kuantitatif. Lokasi penelitian ini di SMPN1 Tarusan Kabupaten Pesisir Selatan Provinsi Sumatera Barat. Teknik pengambilan sampel pada penelitian dengan Purvosive Sampling. Sampel pada penelitian ini yaitu Siswa, guru Geografi dan Wakil Kurikulum. Berdsarkan hasil penelitian menunjukan bahwa: tingkat pengetahuan siswa itu tergolong cukup baik dengan persentase $77,14 \%$ dan tingkat pengetahuan guru nya cukup baik juga dengan persentase 76,79\%. Untuk kebijakan sekolah siaga bencana di SMP N 1 Tarusan pada tingka siswa tergolong Rendah sekali pada parameter kebijakan dengan persentase $11,42 \%$, tergolong sangat rendah juga pada parameter rencana tanggap darurat dengan persentase $31,66 \%$ dan $20 \%$ pada parameter mobilisasi sumberdaya berarti juga tergolong rendah sekali sedangkan kebijakan sekolah siaga bencana di SMP N 1 Tarusan pada tingkat guru tergolong Rendah sekali pada parameter kebijakan dengan persentase 30,36\%, tergolong sangat rendah juga pada parameter rencana tanggap darurat dengan persentase $22,92 \%$ dan $17,5 \%$ pada parameter mobilisasi sumberdaya berarti juga tergolong rendah sekali.
\end{abstract}

\section{Kata Kunci : Sekolah Siaga Bencana}

\section{PENDAHULUAN}

Program Pengurangan Risiko Bencana (PRB) berbasis sekolah bertujuan menciptakan komunitas sekolah yang siaga terhadap bencana (International Strategy Disaster Reduction / ISDR, 2005). Agar hal tersebut tercapai, Pendidikan PRB bertujuan membangun pemahaman pada peserta didik dan komunitas sekolah tentang penyebab, sifat dan dampak dari bahaya. Selain itu juga mendorong berbagai kompetensi dan keterampilan yang memungkinkan peserta didik dapat berkontribusi secara proaktif dalam kesiapsiagaan dan mitigasi bencana. Pengetahuan dan keterampilan perlu diinformasikan melalui sikap dan nilai-nilai yang mendorong peserta didik untuk bertindak pro-sosial, bertanggung jawab dan responsif ketika keluarga dan komunitasnya terancam. Prioritas program PRB dapat diterapkan melalui sektor pendidikan yaitu dalam pendidikan PRB di sekolah. Karena sekolah merupakan ruang publik yang dapat menjangkau semua tingkatan masyarakat. Pendidikan PRB dapat diaplikasikan dengan menggunakan pengetahuan, kemauan dan motivasi, berlatih keterampilan serta sikap. Dimana akan menjadi kebiasaan atau pengalaman peserta didik dalam menghadapi bencana, sehingga menumbuhkan budaya kesiapsiagaan terhadap bencana di komunitas sekolah. Sekolah Siaga Bencana (SSB) yang merupakan kegiatan untuk membangun komunitas sekolah melalui penguatan pengetahuan dan sikap, kebijakan sekolah, rencana tanggap darurat, sistem peringatan dini sekolah, dan mobilisasi sumber daya berdasarkan kapasitas sekolah yang ada dalam mengantisipasi risiko bencana.

Sumatera Barat merupakan salah satu daerah rawan gempa di Indonesia. Hal ini disebabkan karena letaknya yang berada pada jalur patahan Semangko, tepat di antara pertemuan 
dua lempeng benua besar, yaitu Eurasia dan Indo-Australia. Oleh karenanya, wilayah ini sering mengalami gempa bumi. Gempa bumi besar yang terjadi akhir-akhir ini di Sumatera Barat di antaranya adalah Gempa bumi 30 September 2009 dan Gempa bumi Kepulauan Mentawai 2010. Kabupaten Pesisir Selatan merupakan Kabupaten yang paling rawan terkena bencana Gempa dan Tsunami. Letak geografis Kabupaten Pesisir Selatan terletak di pinggir pantai, dengan garis pantai sepanjang 218 kilometer Topografinya terdiri dari dataran, gunung dan perbukitan yang merupakan perpanjangan gugusan Bukit Barisan. Rawan bencana adalah kondisi atau karakteristik geologis, biologis, hidrologis, klimatologis, geografis, sosial, budaya, politik, ekonomi, dan teknologi pada suatu wilayah untuk jangka waktu tertentu yang mengurangi kemampuan mencegah, meredam, mencapai kesiapan, dan mengurangi kemampuan untuk menanggapi dampak buruk bahaya tertentu. Potensi bencana yang ada di desa itu salah satunya adalah bencana. Masyarakat sebenarnya cukup tahu dan sadar bahaya yang menimpa karena mereka tinggal di daerah rawan bencana. Salah satu untuk mengurangi risiko rawan bencana ini adalah diadakan nya Sekolah Siaga Bencana di SMPN 1 Tarusan.

\section{METODE}

Jenis penelitian ini adalah kuantitatif. Lokasi penelitian ini di SMPN1 Tarusan Kabupaten Pesisir Selatan Provinsi Sumatera Barat. Adapun populasi dalam penelitian ini adalah seluruh anggota sekolah SMP N 9 Tarusan di Kabupaten Pesisir Selatan. Sedangkan sampel pada penelitian diambil menggunkaan teknik Purvosive Sampling. Sampel pada penelitian ini yaitu Siswa, guru Geografi dan Wakil Kurikulum. Jenis data dalam penelitian adalah data primer dan data sekunder. Data yang diperlukan dalam penelitian ini diperoleh dari SMP N 1 Tarusan Kabupaten Pesisir Selatan Provinsi Sumatera Selatan. Digunakan untuk menggambarkan data sebagaimana adanya. Formula digunakan antara lain: Persentase dengan rumus

$$
\mathrm{P}=\frac{f}{n} \times 100 \%
$$

Keterangan:

$\mathrm{P}=$ Pesentase

$f=$ Frekuensi Jawaban

$n=$ Jumlah Sampel

Kriteria Ketentuan : Untuk akhir analisis data penelitian dengan persentaseoleh Riduwan (2007)

Tabel 1. Interval Tingkat Pengetahuan dan Kebijakan

\begin{tabular}{|l|l|l|}
\hline $\begin{array}{l}\mathrm{N} \\
\mathrm{o}\end{array}$ & Interval $(\%)$ & Persentase \\
\hline & $0-100$ & Sangat tinggi \\
\hline & $0-89$ & Tinggi \\
\hline & $5-79$ & Cukup Tinggi \\
\hline & $55-64$ & Rendah \\
\hline & $0-54$ & Rendah Sekali \\
\hline
\end{tabular}

Sumber : Riduwan,2012

\section{HASIL DAN PEMBAHASAN}

\section{Hasil}

\section{Pengetahuan tentang Sekolah Siaga Bencana}

Pengetahuan tentang bencana ini terdiri dari 21 pertanyaan. Dengan pengskoran 1 untuk jawaban yang benar dan 0 untuk jawaban yang salah. Skor pengetahuan siswa tentang bencana alam diperoleh $77,14 \%$. Adapun pada pertanyaan pertama yaitu Apa yang dimaksud dengan bencana alam adalah $80 \%$. Fenomena alam apa saja yang dapat menimbulkan gempa adalah 100 
$\%$. Apakah penyebab terjadinya gempa aadalah $60 \%$. Apakah bencana yang dapat ditimbulkan akibat gempa adalah 100\%. Meskipun gempa dapat dipredeksi apakah dapat diketahui secara pasti kapan terjadinya adalah 60\%. Apakah yang dimaksud dengan gempa kuat adalah $60 \%$. Apakah ciri-ciri bangunan yang tahan gempa adalah $60 \%$. Langkah apa yang diambil setelah gempa kuat terjadi adalah $80 \%$. Bagaimana cara evakuasi yang baik adalah $0 \%$. Apa yang akan dilakukan saat terjadi gempa ketika berada didalam ruangan adalah 100\%. Apakah gempa akan mengakibatkan terjadinya tsunami adalah 80\%. Apakah tanda-tanda tsunami adalah $100 \%$. Apakah pengertian banjir adalah $80 \%$.

Fenomena yang luar biasa yang bisa menyebabkan korban jiwa, kerusakan lingkungan yang tidak dapat diatasi oleh manusia adalah $100 \%$. Menghindari atau mengurangi resiko dan mempersiapkan diri untuk melakukan upaya tanggap darurat yang efektif adalah $60 \%$. Penyebab terjadinya bencana alam adalah $100 \%$. Pengadaan pemantauan secara teknis untuk mengevaluasi dan merencanakan pemulihan kondisi masyarakat merupakan faktor utama yang menentukan area mana yang harus diberikan prioritas yang pertama untuk dilakukan tindakan adalah $0 \%$. Resiko yang dapat ditimbulkan secara psikologis akibat bencana alam adalah $100 \%$. Penyakit yang akan ditimbulkan dari bencana banjir adalah $100 \%$ dan Tindakan yang dilakukan untuk menghindari resiko bencana banjir yang tinggi adalah $100 \%$.

Berdasarkan hasil penelitian tingkat pengetahuan yang paling rendah berada pada pertanyaan Bagaimana cara evakuasi yang baik dengan persentase $0 \%$, dan Pengadaan pemantauan secara teknis untuk mengevaluasi dan merencanakan pemulihan kondisi masyarakat merupakan faktor utama yang menentukan area mana yang harus diberikan prioritas yang pertama untuk dilakukan tindakan juga $0 \%$. Untuk skor pengrtahuan guru tentang bencana alam diperoleh $76,18 \%$. Adapun pertaanyaan pertama yaitu Apa yang dimaksud dengan bencana alam adalah 75 $\%$. Fenomena alam apa saja yang dapat menimbulkan gempa adalah $75 \%$. Apakah penyebab terjadinya gempa aadalah $75 \%$. Apakah bencana yang dapat ditimbulkan akibat gempa adalah 62,5\%. Meskipun gempa dapat dipredeksi apakah dapat diketahui secara pasti kapan terjadinya adalah $62,5 \%$. Apakah yang dimaksud dengan gempa kuat adalah $50 \%$. Apakah ciri-ciri bangunan yang tahan gempa adalah 12,5\%. Langkah apa yang diambil setelah gempa kuat terjadi adalah $100 \%$. Bagaimana cara evakuasi yang baik adalah 12,5\%. Apa yang akan dilakukan saat terjadi gempa ketika berada didalam ruangan adalah $75 \%$. Apakah gempa akan mengakibatkan terjadinya tsunami adalah 100\%. Apakah tanda-tanda tsunami adalah $100 \%$. Apakah pengertian banjir adalah $87,5 \%$.

Fenomena yang luar biasa yang bisa menyebabkan korban jiwa, kerusakan lingkungan yang tidak dapat diatasi oleh manusia adalah $100 \%$. Menghindari atau mengurangi resiko dan mempersiapkan diri untuk melakukan upaya tanggap darurat yang efektif adalah $62,5 \%$. Penyebab terjadinya bencana alam adalah $87,5 \%$. Pengadaan pemantauan secara teknis untuk mengevaluasi dan merencanakan pemulihan kondisi masyarakat merupakan faktor utama yang menentukan area mana yang harus diberikan prioritas yang pertama untuk dilakukan tindakan adalah $75 \%$. Resiko yang dapat ditimbulkan secara psikologis akibat bencana alam adalah $100 \%$. Penyakit yang akan ditimbulkan dari bencana banjir adalah $100 \%$ dan Tindakan yang dilakukan untuk menghindari resiko bencana banjir yang tinggi adalah 100\% . Berdasarkan hasil penelitian tingkat pengetahuan yang paling rendah itu berada pada pertanyaan Apakah ciri-ciri bangunan yang tahan gempa dan Bagaimana cara evakuasi yang baik sebesar $12,5 \%$.

\section{Info tentang Bencana}

Info tentang bencana ini terdiri dari 4 pernyataan. Dengan pengskoran 1 untuk jawaban pernyataan yang dipilih dan 0 untuk jawabang pernytaan yang tidak dipilih. Berdasarkan hasil pengetahun informasi pengetahuan ketika terjadi bencana persentase paling tinggi yaitu 60\% didapatkan dari melalui media elektronik (TV, Radio dan Koran ) dan yang terendah dari sosialisasi dengan saudara atau tetangga dan pemerintah, LSM. Ketika terjadi bencana persentase paling tinggi yaitu 50\% didapatkan dari melalui media elektronik (TV, Radio dan Koran ) dan yang terendah yaitu dari pemerintah, LSM. Untuk lebih jelasnya dapat dilihat pada gambar di bawah ini: 


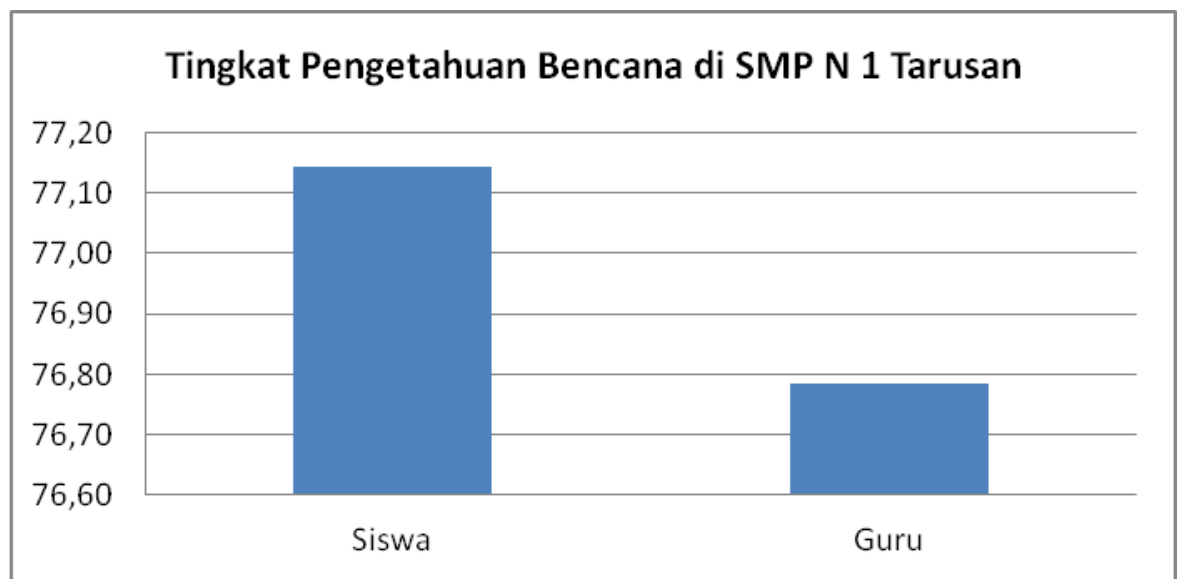

Gambar 1. Diagram Tingkat Pengetahuan Bencana di SMP N 1 Tarusan

Berdasarkan gambar 1, dapat kita simpulkan bahwa tingkat pengetahuan siswa itu tergolong cukup baik dengan persentase $77,14 \%$ dan tingkat pengetahuan guru nya cukup baik juga dengan persentase $76,79 \%$.

\section{Kebijakan Sekolah Siaga Bencana (Siswa)}

3.1 Parameter Kebijakan

Berdasarkan hasil penelitian kebijakan sekolah siaga bencana di SMP N 1 Tarusan adalah $11,42 \%$ dengan indikator yang paling tinggi yaitu Interagsi materi kebencanaan dalam kurikulum dan indikator Kerjasama dengan dinas terkait dengan pesentase $40 \%$.

3.2 Parameter Rencana Tanggap Darurat ( Siswa)

Parameter Rencana Tanggap Darurat ini terdiri dari 12 pernyataan. Dengan pengskoran untuk jawaban yang memilih Ya itu nilai nya 1 dan yang memilih jawaban tidak itu nilai nya 0. Berdasarkan hasil penelitian parameter Rencana Tanggap Darurat di SMP N 1 Tarusan adalah $11,42 \%$ dengan indikator yang paling tinggi yaitu Interagsi materi kebencanaan dalam kurikulum dan indikator Kerjasama dengan dinas terkait dengan pesentase $40 \%$.

3.3 Parameter Mobilisasi Sumberdaya

Parameter Mobilisasi Sumberdaya ini terdiri dari 10 pernyataan. Dengan pengskoran untuk jawaban yang memilih Ya itu nilai nya 1 dan yang memilih jawaban tidak itu nilai nya 0 . Parameter Mobilisasi Sumberdaya dilihat dari siswa di SMP N 1 Tarusan adalah 40\% dengan indikator yang paling tinggi yaitu Adanya gugus siaga bencana sekolah termasuk perwakilan peserta didik dan Membangun karakter peserta didik untuk tangguh bencana dan yang terendah yaitu $0 \%$ pada indikator Pemantulan dan evaluasi partisipatif mengenai kesiagaan sekolah secara rutin (menguji atau melatih kesiagaan sekolah secara berkala) dan Mengembangkan materi kebencanaan dalam proses belajar mengajar. Agar lebih jelasnya kebijakan sekolah siaga bencana SMPN1Tarusan dari faktor siswa dapat dilihat pada gambar di bawah ini:

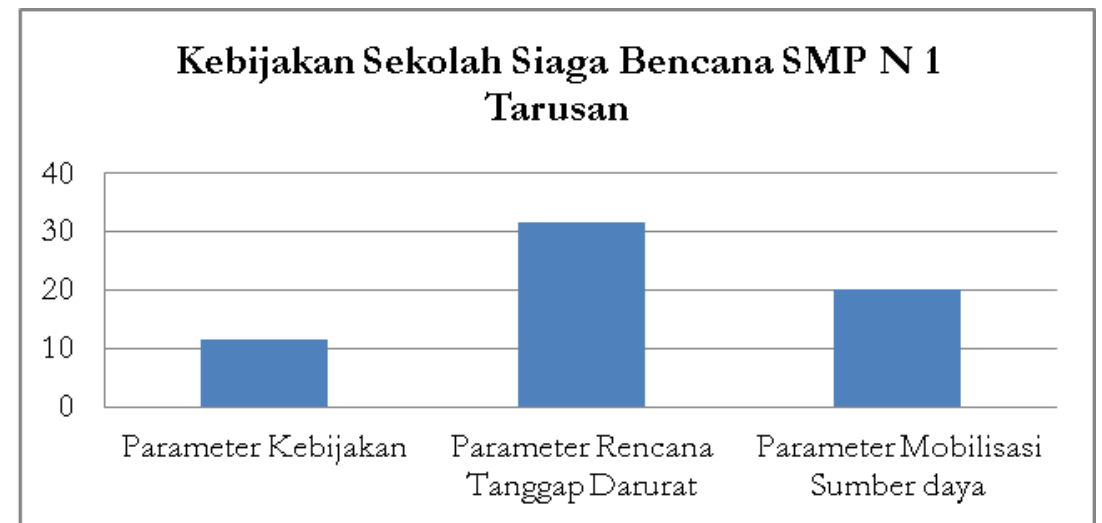

Gambar 2. Kebijakan Sekolah Siaga Bencana SMP N 1 Tarusan (Siswa) 
Berdasarkan gambar 2, dapat kita simpulkan bahwa kebijakan sekolah siaga bencana di SMP N 1 Tarusan pada tingka siswa tergolong Rendah sekali pada parameter kebijakan dengan persentase $11,42 \%$, tergolong sangat rendah juga pada parameter rencana tanggap darurat dengan persentase $31,66 \%$ dan $20 \%$ pada parameter mobilisasi sumberdaya berarti juga tergolong rendah sekali.

3.4 Parameter Kebijakan (Guru)

Berdasarkan hasil penelitian parameter Kebijakan di SMP N 1 Tarusan adalah 62,5\% dengan indikator yang paling tinggi yaitu Adanya kebijakan, kesepakatan, peraturan sekolah yang mendukung upaya kesiagaan di sekolah dan Interagsi materi kebencanaan dalam kurikulum. Sedangkan yang terendah yaitu $0 \%$ pada indikator Pendanaan untuk kebencanaan $1 \%$ dari dan BOS. Untuk lebih jelasnya dapat di lihat pada gambar di bawah ini:

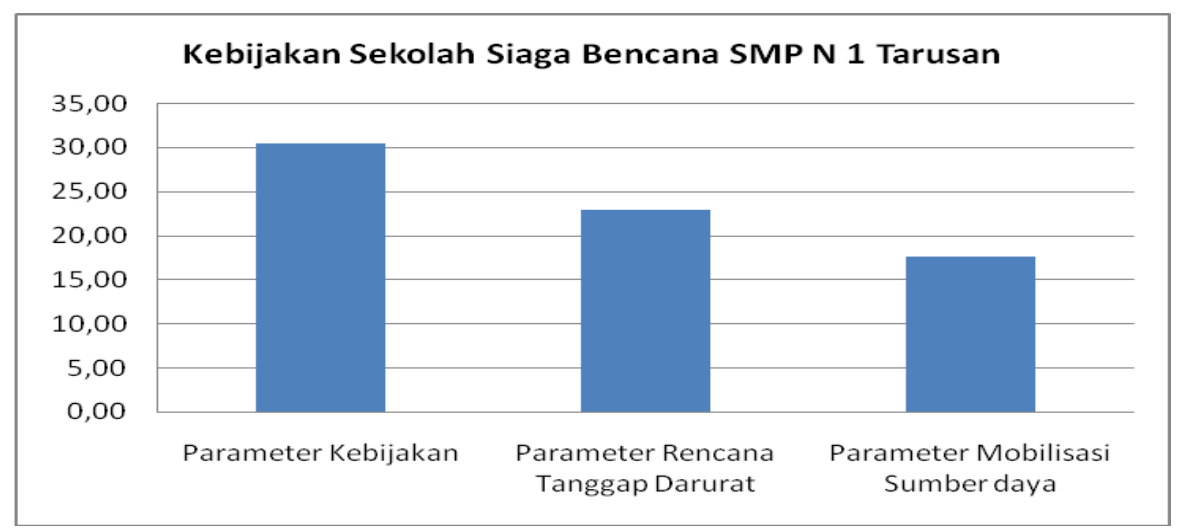

Gambar 3. Kebijakan Sekolah Siaga Bencana SMP N 1 Tarusan (Guru)

Berdasarkan gambar 3, dapat kita simpulkan bahwa kebijakan sekolah siaga bencana di SMP N 1 Tarusan pada tingkat guru tergolong Rendah sekali pada parameter kebijakan dengan persentase $30,36 \%$, tergolong sangat rendah juga pada parameter rencana tanggap darurat dengan persentase $22,92 \%$ dan $17,5 \%$ pada parameter mobilisasi sumberdaya berarti juga tergolong rendah sekali.

\subsection{Parameter Kebijakan Rencana Tanggap Darurat}

Indikator ini terdiri dari 12 pernyataan. Dengan pengskoran nilai 1 untuk jawaban benar dan 0 untuk jawaban salah. Berdasarkan hasil penelitian Rencana Tanggap Darurat di SMP N 1 Tarusan adalah 50\% dengan indikator yang paling tinggi yaitu tersimpan baik, agar dapat tetap ada, meskipun sekolah terkena bencana dan Catatan informasi penting yang mudah digunakan seluruh komponen sekolah, seperti pertolongan darurat terdekat, puskesmas/rumah sakit terdekat, dan aparat terkait. Sedangkan yang terendah yaitu $0 \%$ pada indikator Adanya prosedur tetap kesiapsiagaan sekolah yang disepakati dan dilaksanakan oleh sleuruh kompinen sekolah dan Adanya peta evakuasi sekolah, dengan tanda dan rambu yang terpasang, yang mudah dipahami oeh seluruh komponen sekolah serta Adanya petugas yang bertanggung jawab dan berwenang mengoperasikan alat peringatan dini. Pemeliharaan alat peringatan dini .

\section{KESIMPULAN}

Hasil penelitian ini dapat disimpulkan bahwa tingkat pengetahuan siswa itu tergolong cukup baik dengan persentase $77,14 \%$ dan tingkat pengetahuan guru nya cukup baik juga dengan persentase 76,79\%. Untuk kebijakan sekolah siaga bencana di SMP N 1 Tarusan pada tingka siswa tergolong Rendah sekali pada parameter kebijakan dengan persentase $11,42 \%$, tergolong sangat rendah juga pada parameter rencana tanggap darurat dengan persentase 31,66\% dan $20 \%$ pada 
parameter mobilisasi sumberdaya berarti juga tergolong rendah sekali sedangkan kebijakan sekolah siaga bencana di SMP N 1 Tarusan pada tingkat guru tergolong Rendah sekali pada parameter kebijakan dengan persentase 30,36\%, tergolong sangat rendah juga pada parameter rencana tanggap darurat dengan persentase $22,92 \%$ dan $17,5 \%$ pada parameter mobilisasi sumberdaya berarti juga tergolong rendah sekali.

\section{REFERENSI}

[1] Alhadi, Zikri. 2011. Upaya Pemerintah Kota Padang untuk. Meningkatkan Kesiapsiagaan Masyarakat dalam Menghadapi Ancaman Bencana Gempa dan Tsunami. Tesis tidak diterbitkan. FISIP-UI

[2] Ati ASTUTI. 2015. Pelaksanaan Program Sekolah Siaga Bencana di SMA Negeri 1 Karanganom Klaten. Semarang. Universitas Negeri Semarang.

[3] Asih Dwi Hayu Pangesti. 2012. Gambaran tingkat pengetahuan dan aplikasi kesiapsiagaan bencana pada mahasiswa fakultas ilmu keperawatan universitas Indonesia tahun 2012. Depok. Universitas Indonesia.

[4] Dierektorat Vulkanologi dan Mitigasi Bencana Geologi, Departemen Energi dan Sumber Daya Mineral.Gem pa Bumi dan Tsunami.

[5] Hermon, Dedi. 2012. Mitigasi Bencana Hidrometeorologi. Padang: UNP Press.

[6] Kementrian Pendidikan Nasional. 2010. Strategi Pengurangan Resiko Bencana di Sekolah. Jakarta. Jakarta.

[7] Konsorsium Pendidikan Bencana Indonesia. 2011. Kerangka Kerja Sekolah Siaga Bencana.

[8] Moleong,Jl. 2002. Metodologi Penelitian Kualitatif. Bandung : PT. Remaja Rosda.

[9] Notoatmodjo, S. 2007. Kesehatan Masyarakat Ilmu Dan Seni. Rineka Cipta: Jakarta.

[10] Peraturan Kepala Badan Nasional Penanggulangan Bencana Nomor 4 Tahun 2008 Tentang Pedoman Penyusunan Rencana Penanggulangan Bencana Peraturan Pemerintah Republik Indonesia Nomor 21 Tahun 2008 Tentang Penyelenggaraan Penanggulangan Bencana

[11] Peraturan Kepala Badan Nasional Penanggulangan Bencana Nomor 11 Tahun 2008 Tentang Panduan Rehabilitasi dan Rekonstruksi PascaBencana

[12] Pratama,Putra Ahmad. 2011. Penataan Ruang Berbasis Mitigasi Bencana Kabupaten Kepulauan Mentawai. Jurnal Penanggulangan Bencana Volume 2 Nomor 1.

[13]Pusat Pendidikan Mitigasi Bencana (P2MB) Universitas Pendidikan Indonesia (Online) http://p2mb.geografi.upi.edu/Sekolah Siaga.html.Diakses tanggal 17 oktober 2017.

[14] Sugiyono. 2013. Metode Penelitian Kuantitatif Kualitatif dan R\&D. Bandung: Alfabeta.

[15] Slameto. (2010). Belajar dan Faktor-Faktor Yang Mempengaruhinya. Edisi revisi. Jakarta: Rineka Cipta.

[16] Syafaruddin. 2008. Efektivitas Kebijakan Pendidikan. Jakarta: Rineka Cipta.

[17] Triadmadja, Radianta. 2010. Tsunami. Yogyakarta: Gadjah Mada University Press. 